\title{
КОНСЕРВАТИВНОСТЬ ПОСЛЕДОВАТЕЛЬНОСТЕЙ ГЕНОВ ПОМПЫ МНОЖЕСТВЕННОЙ ЛЕКАРСТВЕННОЙ УСТОЙЧИВОСТИ АСRАВ-TOLС ESCHERICHIA COLI КАК ПРИЗНАК ВОВЛЕЧЕННОСТИ В ПЕРМАНЕНТНУЮ «УБОРКУ» БАКТЕРИАЛЬНОЙ КЛЕТКИ
}

\author{
М. В. Каракозова ${ }^{1 凶}$, П. А. Назаров ${ }^{2}$ \\ 'Медико-генетический научный центр, Москва \\ 2 Научно-исследовательский институт физико-химической биологии имени А. Н. Белозерского, \\ Московский государственный университет имени М. В. Ломоносова, Москва
}

\begin{abstract}
Помпы множественной лекарственной устойчивости (МЛУ) помогают бактериям защищаться от неблагоприятного воздействия окружающей среды. Считается, что гены, кодирующие помпы МЛУ, вариабельны и относятся к так называемым генам «роскоши», т. е. предназначены для адаптации бактерий к изменению окружающих условий. Целью работы было проверить насколько консервативны последовательности генов помпы МЛУ. Для этого проводили анализ последовательностей белков AcrA, AcrB и TolC для различных лабораторных штаммов Escherichia coli. Meтодом выравнивания последовательностей было показано, что штаммы из разных стран, культивируемые в лабораториях уже долгое время, имеют удивительную консервативность последовательностей белков помпы AcrAB-TolC. Она напоминает консервативность генов «домашнего хозяйства», что, по-видимому, говорит о вовлеченности помпы МЛУ AcrAB-TolC в перманентную «уборку» клетки от различных веществ биотического и абиотического происхождения.
\end{abstract}

Ключевые слова: множественная лекарственная устойчивость, антибиотик, АcrAB-TolC, выравнивание последовательностей, Escherichia coli, помпа, транспортер, биоцид, гены «роскоши», гены «домашнего хозяйства»

Благодарности: авторы благодарят студентов (Джафарову Т., Мамедову Д., Маушева Ф., Миранян К., Омарову Д. и Родионову Э.) и сотрудников кафедры морфологии и патологии Московского медицинского университета «Реавиз» за предварительные данные, их анализ и дискуссию.

$\triangle$ Для корреспонденции: Марина Викторовна Каракозова

Микрорайон 1-й, д. 15, кв. 43, г. Зарайск, Зарайский р-н, Московская обл., 140601; mvk752002@gmail.com

Статья получена: 19.02.2018 Статья принята к печати: 30.03.2018

DOI: 10.24075/vrgmu.2018.024

\section{CONSERVED SEQUENCES OF GENES CODING FOR THE MULTIDRUG RESISTANCE PUMP ACRAB-TOLC OF ESCHERICHIA COLISUGGEST THEIR INVOLVEMENT INTO PERMANENT CELL "CLEANING"}

Karakozova $\mathrm{MV}^{1} \otimes$, Nazarov $\mathrm{PA}^{2}$

Research Centre of Medical Genetics, Moscow

${ }^{2}$ Belozersky Institute of Physico-Chemical Biology,

Lomonosov Moscow State University, Moscow

\begin{abstract}
Multidrug resistance pumps (MDR pumps) of bacteria confer protection against aggressive environmental factors. The genes coding for MDR pumps are thought to be variable. They belong to the group of the so-called contingency genes, i.e are necessary for bacterial adaptation to the changing environment. The aim of the present work was to establish how conserved are the sequences of genes coding for MDR pumps. We analyzed the sequences of AcrA, AcrB and TolC proteins of different Escherichia coli strains. Using sequence alignment tools, we demonstrated that strains originating in different countries and cultured in the labs for a long time are amazingly conserved in terms of AcrAB-TolC sequences. They resemble housekeeping genes, suggesting the involvement of the AcrAB-TolC pump into permanent "cleaning" of various biotic and abiotic agents.
\end{abstract}

Keywords: multidrug resistance, antibiotic, AcrAB-ToIC, sequence alignment, Escherichia coli, pump, transporter, biocide, contingency genes, housekeeping genes

Acknowledgement: the authors wish to thank students (Dzhafarova T, Mamedova D, Maushev F, Miranian K, Omarova D and Rodionova E) and the Department of Morphology and Pathology of Medical Institute REAVIZ for the provided data, their analysis and discussion.

$\triangle$ Correspondence should be addressed: Marina Karakozova

Microrayon 1, d.15, kv. 43, Zaraisk, Zaraiski r-n, Moscow region, 140601; mvk752002@gmail.com

Received: 19.02.2018 Accepted: 30.03.2018

DOI: $10.24075 /$ brsmu.2018.024

Грамотрицательная гамма-протеобактерия Escherichia coli (E. coli) была впервые обнаружена в 1885 г. Теодором Эшерихом в стуле здоровых пациентов [1]. В природе E. coli распространена в нижнем отделе кишечника теплокровных организмов и служит важным объектом научных исследований. В настоящее время четыре штамма E. coli (K-12, B, W и C) используют в качестве модельных организмов. Штамм К-12 был получен в 1922 г. сотрудниками Стэнфордского университета [2]. Штамм В описан в 1918 г. ДЭрелем в Институте Пастера в Париже [3]. О двух других, 
менее распространенных штаммах, сообщили в 1951 г. Маргарет Лейб (штамм С) [4, 5] и в 1943 г. Селман Ваксман (штамм W) [6]. Наиболее распространенные и известные штаммы принадлежат к группе K-12 и В. Лабораторные штаммы в ходе своей «эволюции» в условиях научных лабораторий оказались лишены ряда свойств, например образования биопленок на абиотических поверхностях, что сделало их удобным объектом для исследований, в том числе поиска антибиотиков [7]. Под действием комбинации естественного и искуственного отбора в лабораторных условиях были получены множественные производные штаммов К-12 и В, которые хорошо известны и используются исследователями повсеместно (табл. 1). Примерами производных штамма В могут служить известные штаммы BL21 и BL21(DE3), а штамма K-12 DH5 $\alpha$, JM109, W3110, XL-1 Blue, MG1655.

В настоящее время перед учеными стоит сложная задача поиска либо новых антибиотиков, либо эффективной их замены. Одно из наиболее перспективных направлений выявление ингибиторов помп множественной лекарственной устойчивости (МЛУ), отвечающих за активное удаление антибиотиков из бактериальной клетки. Данные, полученные на делеционных (нокаутных) мутантах, свидетельствуют: удаление генов, кодирующих помпы МЛУ может приводить к многократному снижению минимально действующей концентрации антибиотика [8], что имеет положительные аспекты в результате уменьшения как финансовых затрат на лечение пациента, так и токсичного действия антибиотикотерапии на организм. Хотя в настоящее время существует довольно много работ, посвященных исследованию влияния помп МЛУ на действие различных антибактериальных агентов, есть большой перечень объективных причин, которые не позволяют сравнивать данные, полученные в ходе исследований, друг с другом. К таким факторам можно отнести различный генетический фон штаммов, на которых проводилось исследование. Даже в случае близкородственных штаммов W3110 и MG1655 [9] существует более 200 различных модификций генома, что затрудняет сравнение результатов. В силу того, что фактором, влияющим на резистентность, служит наличие или отсутствие определенной помпы, мы предположили, что для всех штаммов E. coli c идентичными последовательностями помпы МЛУ будет иметь место сопоставимая или равная резистентность. Для исследования выбрали помпу МЛУ AcrAB-TolC. Таким образом, целью работы было сравнение последовательностей белков AcrA, AcrB и TolC у разных лабораторных штаммов E. coli и при наличии мутаций в них - изучение взаимосвязи между мутациями и резистентностью.

\section{МАТЕРИАЛЫ И МЕТОДЫ}

\section{Выбор объектов исследования}

В качестве объектов исследования мы выбрали штаммы группы K-12: W3110, MG1655, NEB 5-alpha, MDS42, GM4792, AG100, MC4100, DH10B, ER3413, HMS174, BW2952, BW25113, и штамм группы B - BL21(DE3), чьи белковые последовательности генов acrA, acrB, tolC известны и депонированы (табл. 2).

\section{Выбор референсной последовательности}

При выборе референсной последовательности мы приняли во внимание наличие большого числа делеционных мутантов у штамм E. coli str. K-12 substrain BW25113. Штамм является базовым для коллекции делеционных мутантов Kеiо, включающей в себя штаммы с делециями 3985 генов из 4288 генов E. coli [10]. В качестве ресреренсной последовательности АсrА выбрали последовательность AIN30961.1, референсной последовательности AcrB выбрали последовательность AIN30960.1 и референсной последовательности TolC — последовательность AIN33386.1.

\section{Выравнивание последовательности}

Анализ последовательностей осуществляли с использованием стандартных средств поиска локальных выравниваний NCBI BLASTp с функцией множественного сравнения [11], а также с использованием функции сравнения последовательностей программы STRING [12]. Визуализацию проводили с помощью программы NCBI MSA Viewer [13]. Последовательности каждого белка-компонента выравнивали относительно референсной последовательности.

\section{РЕЗУЛЬТАТЫ ИССЛЕДОВАНИЯ}

Известно, что бактериальная резистентность может являться результатом нескольких процессов: 1) накопления генов резистентности на плазмидах; 2) увеличения уровня экспрессии генов, кодирующих помпы МЛУ; 3) дупликации

Таблица 1. Географическое происхождение геномов E. coli

\begin{tabular}{|l|l|l|}
\hline \multicolumn{1}{|c|}{ Штамм } & \multicolumn{1}{|c|}{ Организация } & \multicolumn{1}{|c|}{ Город, страна } \\
\hline MG1655 & University of Wisconsin & Милуоки, США \\
\hline W3110 & Nara Institute of Science and Technology & Икома, Япония \\
\hline BL21(DE3) & Korea Research Institute of Bioscience and Biotechnology & Теджон, Южная Корея \\
\hline MDS42 & Osaka University & Осака, Япония \\
\hline MC4100 & University of Kiel, Germany & Киль, Германия \\
\hline BW25113 & Universite de Sherbrooke, Canada & Шербрук, Канада \\
\hline ER3413 & New England Biolabs & Ипсвич, США \\
\hline AG100 & University of Exeter & Эксетер, Великобритания \\
\hline NEB 5-alpha & New England Biolabs & Ипсвич, США \\
\hline HMS174 & Austrian Centre of Industrial Biotechnology & Грац, Австрия \\
\hline BW2952 & Nankai University & Нанкай, Китай \\
\hline DH10B & University of Wisconsin-Madison & Мадисон, США \\
\hline GM4792 & Beijing Normal University & Пекин, Китай \\
\hline
\end{tabular}


Таблица 2. Коды доступа (accession numbers) к депонированным белковым последовательностям генов acrA, acrB и to/C

\begin{tabular}{|c|c|c|c|c|}
\hline Субштамм & Штамм & AcrA & AcrB & ToIC \\
\hline MG1655 & $K-12$ & NP_414996.1 & NP_414995.1 & NP_417507.2 \\
\hline W3110 & $K-12$ & BAE76242.1 & BAE76241.1 & BAE77091.1 \\
\hline NEB 5-alpha & $K-12$ & AOO68785.1 & AOO68784.1 & AOO71261.1 \\
\hline MDS42 & $K-12$ & BAL37669.1 & BAL37668.1 & BAL39694.1 \\
\hline GM4792 & $K-12$ & AKK16793.1 & AKK13611.1 & AKK18828.1 \\
\hline AG100 & $K-12$ & CQR80062.1 & CQR80061.1 & CQR82466.1 \\
\hline MC4100 & $K-12$ & CDJ70932.1 & CDJ70931.1 & CDJ73817.1 \\
\hline DH10B & $K-12$ & ACB01590.1 & ACB01589.1 & ACB04120.1 \\
\hline ER3413 & $K-12$ & AIZ54314.1 & AIZ54313.1 & AIZ52829.1 \\
\hline HMS174 & $K-12$ & CDY55568.1 & CDY55565.1 & CDY61615.1 \\
\hline BW2952 & $K-12$ & ACR63806.1 & ACR63808.1 & ACR65687.1 \\
\hline BW25113 & $K-12$ & AIN30961.1 & AIN30960.1 & AIN33386.1 \\
\hline BL21(DE3) & $B$ & ACT42313.1 & ACT42312.1 & ACT44711.1 \\
\hline
\end{tabular}

генов; 4) накопления мутаций $[14,15]$. Изменение уровня экспрессии и накопление мутаций в генах, кодирующих помпы МЛУ, могут определяться точечными мутациями в аминокислотных последовательностях белков. Таким образом, изменение бактериальной резистентности может быть предсказано на основе анализа последовательностей.

Бактериальные гены подразделяются на гены «домашнего хозяйства» (housekeeping genes), обеспечивающие поддержание важнейших функций клетки и гены «роскоши» (contingency genes), которые играют важную роль в адаптации бактерий к изменяющимся условиям окружающей среды. Гены «домашнего хозяйства» обычно мутируют с низкой частотой, тогда как гены «роскоши» обладают высокой частотой мутации [16]. Считается, что гены помп МЛУ относятся к генам «роскоши», поэтому должны иметь довольно большую вариабельность первичной структуры белков, кодируемых ими. Так как лабораторные штаммы обычно подвержены давлению искусственного отбора, вызванного использованием различных биоцидов и мутагенов, можно предположить, что культивируемые на протяжении почти 100 лет штаммы и их производные, используемые в лабораториях различных стран, будут довольно сильно различаться по аминокислотному полиморфизму. Сравниваемые штаммы происходят из разных стран и континентов (табл. 1), поэтому можно предположить наличие мутаций в каком-либо из генов помпы МЛУ AcrAB-TolC.

Однако проведенный нами анализ выравнивания последовательностей белков AcrA (рис. 1), AcrB (рис. 2) и TolC (рис. 3) субштамма BW25113 и последовательностей штамма K-12 (субштаммы W3110, MG1655, NEB 5-alpha, MDS42, GM4792, AG100, MC4100, DH10B, ER3413, HMS174, BW2952) и штамма B (субштамм BL21(DE3)), показал отсутствие полиморфизмов во всех трех белках помпы МЛУ AcrAB-TolC, независимо от того, принадлежит субштамм к производным штамма K-12 или штамма В.

Принимая во внимание тот фракт, что частота мутирования у E. coli составляет $\sim 1 \times 10^{-3}$ на геном за деление [17] а, по другой оценке, даже чуть выше (3-4×10-3 на геном за деление) [18], можно предположить, что последовательность помпы AcrAB-TolC консервативна. Идентичность последовательностей составила 100\% при одинаковой длинне покрытия для каждого из исследуемых белков (397 аминокислотных остатков - для AcrA, 1049 аминокислотных остатков - для AcrB и 493 аминокислотных остатка - для TolC).

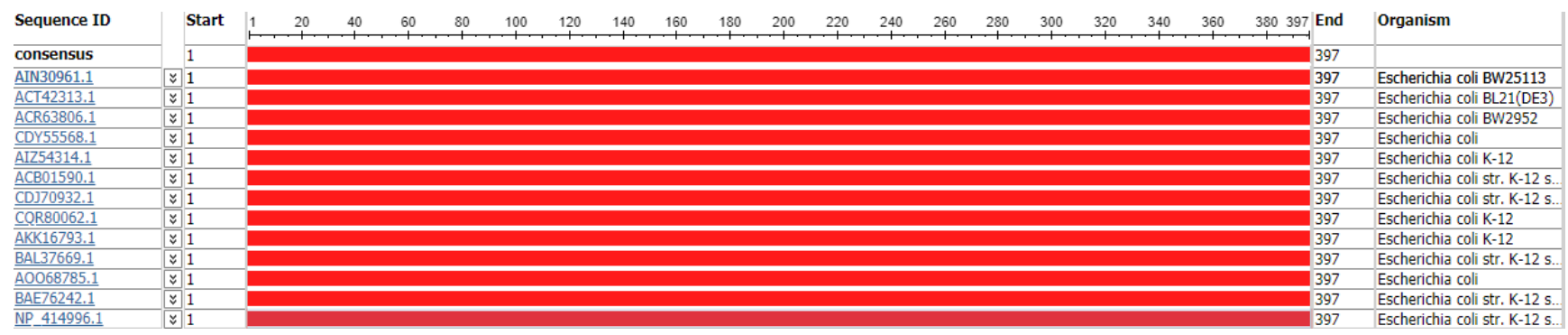

Рис. 1. Выравнивание последовательности белка АсrА субштамма BW25113 относительно последовательностей белка АсгА производных штаммов К-12 и В

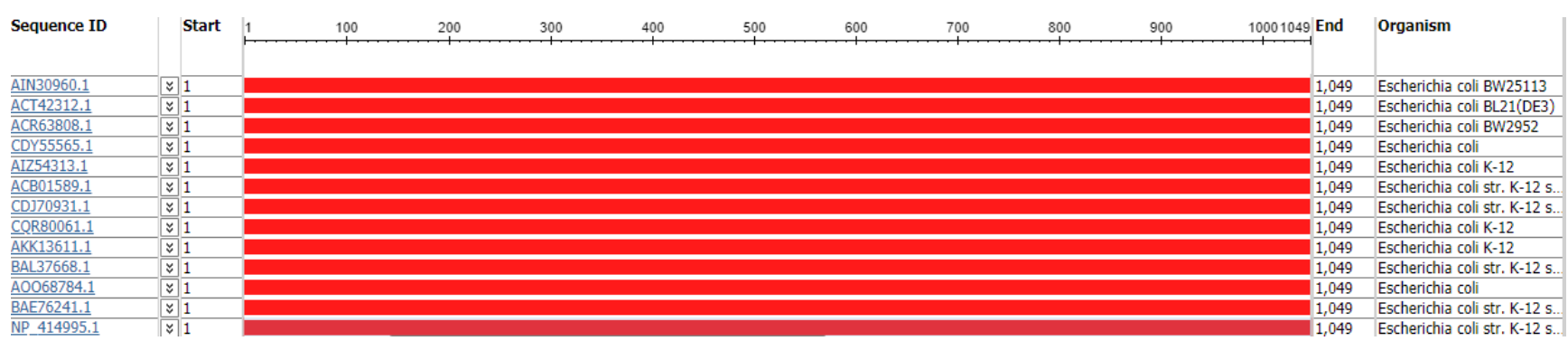

Рис. 2. Выравнивание последовательности белка АсrВ субштамма BW25113 относительно последовательностей белка АсгВ производных штаммов К-12 и В 


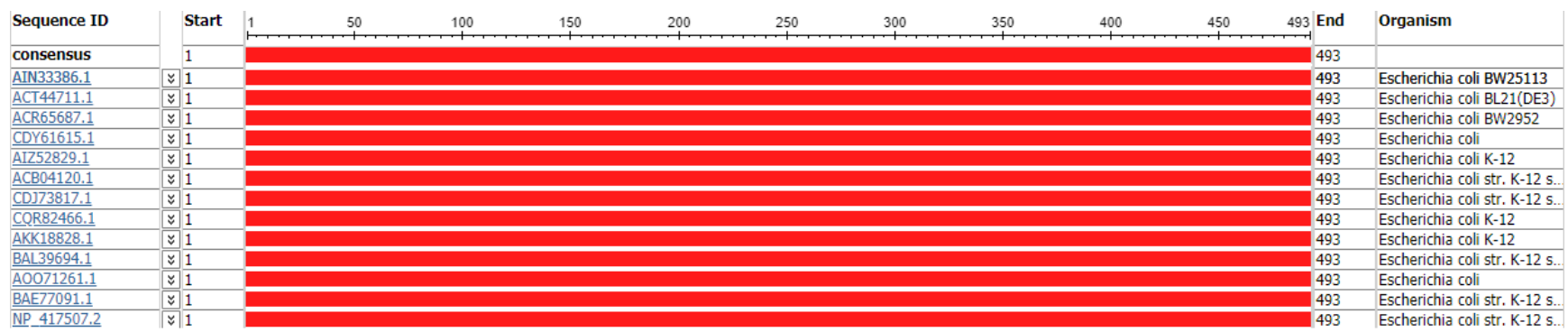

Рис. 3. Выравнивание последовательности белка ToIC субштамма BW25113 относительно последовательностей белка ТоIC производных штаммов K-12 и B

\section{ОБСУЖДЕНИЕ РЕЗУЛЬТАТОВ}

Согласно современной классификации, штаммы группь В и K-12 относят к одной филогенетической группе А [19], что могло бы объяснить сходство аминокислотных последовательностей всех трех белков, однако не их идентичность. Из полученных нами результатов можно сделатьвыводоналичииконсенсуснойпоследовательности очень консервативного ансамбля помпы МЛУ АсrАВTolC. Таким образом, выбранные нами референсные последовательности белков AcrA (AIN30961.1), АcrB (AIN30960.1), и TolC (AIN33386.1) являются консенсусными для исследуемых штаммов E. coli.

Обнаруженные в работе последовательности будут являться консенсусными для представителей всей филогенетической группы A, а возможно и других филогенетических групп (B1, В2, D, и Е), что может быть использовано в дальнейшем для нормирования исследованных последовательностей относительно консенсусной.

Отсутствие точечных мутаций в генах, кодирующих белки-компонентыпомпыAcrAB-TolC, длявсехисследуемых штаммов свидетельствует о жестком контроле отбора, как и в случае с генами "домашнего хозяйства». Такой контроль особенно важен для основной помпы МЛУ E. coli AcrAB-TolC, отвечающей за удаление различных веществ, таких как бензалкония хлорид, бромистый этидий, индол, гексан, антибиотики (эритромицин, ципрофлоксацин и т. д.), родамин, берберин, а также трифенилфосфоний и его производные [20-21].

Необходимо отметить, что было бы неправильно рассматривать гены МЛУ только как гены, отвечающие за резистентность к биоцидам. Было показано их немаловажное значение в колонизации и персистенции бактерий [22], поэтому их роль не ограничена функцией защиты от антибактериальных агентов. По-видимому, продукты генов МЛУ выполняют рутинную работу по защите бактериальной клетки от различных веществ биотического и абиотического происхождения и заслуженно могут быть рассмотрены как своеобразные гены «домашнего хозяйства», занятые перманентной "уборкой», а не как гены «роскоши», включающиеся в работу только в определенный период времени.

\section{ВЫВОДЬ}

Полученные данные позволяют говорить об исключительной роли, которую выполняет в клетке E. coli помпа МЛУ AcrAB-TolC, последовательность белков которой оказалась неожиданно сверхконсервативной. Это позволяет рассматривать работу помпы МЛУ AcrAB-TolC под иным углом - как постоянную защиту бактериальной клетки от различных факторов окружающей среды; от работы помпы МЛУ зависит не только резистентность бактерии к антибиотикам и их альтернативам, но и само выживание бактерии.

\section{Литература}

1. Escherich T. Die Darmbakterien des Neugeborenen und Säuglinge. Fortschr. Med. 1885; 3: 515-522.

2. Daegelen P, Studier FW, Lenski RE, Cure S, Kim JF. Tracing ancestors and relatives of Escherichia coli $\mathrm{B}$, and the derivation of B strains REL606 and BL21(DE3). J Mol Biol. 2009; 394 (4): 634-43.

3. Bachmann BJ. Pedigrees of Some Mutant Strains of Escherichia coli K-12. Bacteriological Reviews, 1972; 36 (4): 525-557.

4. Lieb M, Weigle JJ, Kellenberger E. A study of hybrids between two strains of Escherichia coli. Journal of Bacteriology. 1955; 69 (4): 468-471.

5. Lieb M. Forward and Reverse Mutation in a Histidine-Requiring Strain of Escherichia Coli Genetics. 1951; 36 (5): 460-477.

6. Archer CT, Kim JF, Jeong H, Park JH, Vickers CE, Lee SY, et al. The genome sequence of E. coli W (ATCC 9637): comparative genome analysis and an improved genome-scale reconstruction of E. coli. BMC Genomics. 2011; 12: 9.

7. Vidal O, Longin R, Prigent-Combaret C, Dorel C, Hooreman M, Lejeune P. Isolation of an Escherichia coli K-12 mutant strain able to form biofilms on inert surfaces: involvement of a new ompR allele that increases curli expression. J Bacteriol. 1998; 180 (9): 2442-2449.

8. Sulavik MC, Houseweart C, Cramer C, Jiwani N, Murgolo N, Greene J, et al. Antibiotic susceptibility profiles of Escherichia coli strains lacking multidrug efflux pump genes. Antimicrob Agents
Chemother. 2001; 45 (4): 1126-1136.

9. Hayashi K, Morooka N, Yamamoto Y, Fujita K, Isono K, Choi S, et al. Highly accurate genome sequences of Escherichia coli K-12 strains MG1655 and W3110. Mol Syst Biol. 2006; 2: 2006.0007.

10. Baba T, Ara T, Hasegawa M, Takai Y, Okumura Y, Baba M, et al. Construction of Escherichia coli K-12 in-frame, single-gene knockout mutants: the Keio collection. Mol Syst Biol. 2006; 2: 2006.0008.

11. BLASTp (https://blast.ncbi.nlm.nih.gov/Blast.cgi?PROGRAM=blastp\& PAGE_TYPE=BlastSearch\&LINK_LOC=blasthome)

12. Szklarczyk D, Morris JH, Cook H, Kuhn M, Wyder S, Simonovic M, et al. The STRING database in 2017: quality-controlled proteinprotein association networks, made broadly accessible. Nucleic Acids Res. 2017; 45: D362-68.

13. Multiple Sequence Alignment Viewer v. 1.7.7 (https://www.ncbi. nlm.nih.gov/tools/msaviewer/about//

14. Nikaido H. Multidrug Resistance in Bacteria. Annu Rev Biochem. 2009; 78: 119-146

15. Martinez JL, Baquero $F$ Mutation frequencies and antibiotic resistance. Antimicrob Agents Chemother. 2000; 44 (7): 17711777

16. Moxon ER, Rainey PB. Nowak MA. Lenski RE. Adaptive evolution of highly mutable loci in pathogenic bacteria. Curr Biol. 1994; 4: 24-33.

17. Lee H, Popodi E, Tang H, Foster PL. Rate and molecular spectrum 
of spontaneous mutations in the bacterium Escherichia coli as determined by whole-genome sequencing. Proc Natl Acad Sci USA, 2012; 109 (41): E2774-E2783.

18. Drake JW. A constant rate of spontaneous mutation in DNAbased microbes. Proc Natl Acad Sci USA, 1991; 88: 7160-7164.

19. Sims GE, Kim S.-H. Whole-genome phylogeny of Escherichia coli/Shigella group by feature frequency profiles (FFPs) Proc Natl Acad Sci U S A. 2011; 108 (20): 8329-8334.

\section{References}

1. Escherich T. Die Darmbakterien des Neugeborenen und Säuglinge. Fortschr. Med. 1885; 3: 515-522.

2. Daegelen P, Studier FW, Lenski RE, Cure S, Kim JF. Tracing ancestors and relatives of Escherichia coli $\mathrm{B}$, and the derivation of B strains REL606 and BL21(DE3). J Mol Biol. 2009; 394 (4): 634-43.

3. Bachmann BJ. Pedigrees of Some Mutant Strains of Escherichia coli K-12. Bacteriological Reviews, 1972; 36 (4): 525-557.

4. Lieb M, Weigle JJ, Kellenberger E. A study of hybrids between two strains of Escherichia coli. Journal of Bacteriology. 1955; 69 (4): 468-471.

5. Lieb M. Forward and Reverse Mutation in a Histidine-Requiring Strain of Escherichia Coli Genetics. 1951; 36 (5): 460-477.

6. Archer CT, Kim JF, Jeong H, Park JH, Vickers CE, Lee SY, et al. The genome sequence of E. coli W (ATCC 9637): comparative genome analysis and an improved genome-scale reconstruction of E. coli. BMC Genomics. 2011; 12: 9.

7. Vidal O, Longin R, Prigent-Combaret C, Dorel C, Hooreman M, Lejeune P. Isolation of an Escherichia coli K-12 mutant strain able to form biofilms on inert surfaces: involvement of a new ompR allele that increases curli expression. J Bacteriol. 1998; 180 (9): 2442-2449.

8. Sulavik MC, Houseweart C, Cramer C, Jiwani N, Murgolo N, Greene J, et al. Antibiotic susceptibility profiles of Escherichia col strains lacking multidrug efflux pump genes. Antimicrob Agents Chemother. 2001; 45 (4): 1126-1136.

9. Hayashi K, Morooka N, Yamamoto Y, Fujita K, Isono K, Choi S, et al. Highly accurate genome sequences of Escherichia coli K-12 strains MG1655 and W3110. Mol Syst Biol. 2006; 2: 2006.0007.

10. Baba T, Ara T, Hasegawa M, Takai Y, Okumura Y, Baba M, et al. Construction of Escherichia coli K-12 in-frame, single-gene knockout mutants: the Keio collection. Mol Syst Biol. 2006; 2: 2006.0008 .

20. Pos KM. Drug transport mechanism of the AcrB efflux pump. Biochim Biophys Acta. 2009; 1794 (5): 782-793.

21. Nazarov PA, Osterman IA, Tokarchuk AV, Karakozova MV Korshunova GA, Lyamzaev KG et al. Mitochondria-targeted antioxidants as highly effective antibiotics. Sci Rep. 2017; 7 (1): 1394.

22. Piddock LJ Multidrug-resistance efflux pumps - not just for resistance. Nat Rev Microbiol. 2006; 4 (8): 629-36.

11. BLASTp (https://blast.ncbi.nlm.nih.gov/Blast.cgi?PROGRAM=blastp\& PAGE_TYPE=BlastSearch\&LINK_LOC=blasthome)

12. Szklarczyk D, Morris JH, Cook H, Kuhn M, Wyder S, Simonovic M, et al. The STRING database in 2017: quality-controlled proteinprotein association networks, made broadly accessible. Nucleic Acids Res. 2017; 45: D362-68.

13. Multiple Sequence Alignment Viewer v. 1.7.7 (https://www.ncbi. nlm.nih.gov/tools/msaviewer/about/s

14. Nikaido H. Multidrug Resistance in Bacteria. Annu Rev Biochem. 2009; 78: 119-146.

15. Martinez JL, Baquero $F$ Mutation frequencies and antibiotic resistance. Antimicrob Agents Chemother. 2000; 44 (7): 17711777.

16. Moxon ER, Rainey PB. Nowak MA. Lenski RE. Adaptive evolution of highly mutable loci in pathogenic bacteria. Curr Biol. 1994; 4: 24-33.

17. Lee H, Popodi E, Tang H, Foster PL. Rate and molecular spectrum of spontaneous mutations in the bacterium Escherichia coli as determined by whole-genome sequencing. Proc Natl Acad Sci USA, 2012; 109 (41): E2774-E2783.

18. Drake JW. A constant rate of spontaneous mutation in DNAbased microbes. Proc Natl Acad Sci USA, 1991; 88: 7160-7164.

19. Sims GE, Kim S.-H. Whole-genome phylogeny of Escherichia coli/Shigella group by feature frequency profiles (FFPs) Proc Natl Acad Sci U S A. 2011; 108 (20): 8329-8334.

20. Pos KM. Drug transport mechanism of the AcrB efflux pump. Biochim Biophys Acta. 2009; 1794 (5): 782-793.

21. Nazarov PA, Osterman IA, Tokarchuk AV, Karakozova MV, Korshunova GA, Lyamzaev KG et al. Mitochondria-targeted antioxidants as highly effective antibiotics. Sci Rep. 2017; 7 (1): 1394.

22. Piddock LJ Multidrug-resistance efflux pumps - not just for resistance. Nat Rev Microbiol. 2006; 4 (8): 629-36. 